\title{
O ACRE NÃO EXISTE? NAS DESNOTÍCIAS, NÃO
}

\author{
Ana Cristina Carmelino* \\ Universidade Federal de São Paulo \\ Departamento de Letras \\ São Paulo, SP, Brasil \\ Karine Silveira** \\ Pontifícia Universidade Católica de Minas \\ Departamento de Letras \\ Belo Horizonte, MG, Brasil
}

\begin{abstract}
Resumo: Neste artigo, o objetivo é mostrar que a referenciação feita por expressões nominais referenciais elou referenciais e atributivas é capaz de construir determinada identidade social para o estado do Acre. Para isso, analisam-se desnotícias, nome dado a textos humorísticos publicados no site Desciclopédia que parodiam notícias escritas por mídias de renome. A discussão teórica ancora-se especialmente nos conceitos de identidade social e referenciação, formulados, respectivamente, pela Análise de Discurso Crítica e pela Linguística Textual. O estudo explicita que a seleção de termos que compõem as expressões nominais é responsável por gerar certos efeitos de sentido. No caso em análise, busca-se construir identidades sociais de modo bem-humorado, visto que tais formas colocam em questão a existência do Acre, tornando esse estado motivo de piada.
\end{abstract}

Palavras-chave: Identidade social. Referenciação. Desnoticia. Humor. Acre.

10 ACRE EM QUESTÃO

Diversos são os motivos para se fazer piada ${ }^{1}$ com algo ou alguém, a saber: brincar, rebaixar, criticar; escancarar comportamentos não admitidos de forma explícita, mas praticados socialmente; forjar ou dissimular, para expressar efeitos de verdade; e difundir práticas sociais enraizadas na cultura de um povo, modos de ser, construções identitárias. Nota-se, curiosamente, que dentre os estados brasileiros, o Acre tem sido alvo constante de piada na Internet. Comecemos com dois exemplos, a fim de ilustrar o tipo de brincadeira comumente feita com esse estado:

\footnotetext{
* Professora Adjunta IV da área de Estudos da Linguagem. Doutora em Linguística e Língua Portuguesa pela Unesp/CAr. E-mail: anacriscarmelino@gmail.com

** Doutoranda em Linguística e Língua Portuguesa pela PUC - Minas. E-mail: karineletras@bol.com.br

${ }^{1}$ Estamos usando o conceito de piada da forma mais ampla possível, ou seja, algo constituinte de textos humorísticos e compartilhado por diferentes gêneros de cunho cômico. É preciso destacar também que os termos "humor", "brincadeira", "piada" e "cômico" (e suas variantes) são usados aqui como sinônimos.
} 


\section{Figura 1 - Exemplo (1): Mapa do Brasil (visto pelos cariocas)}

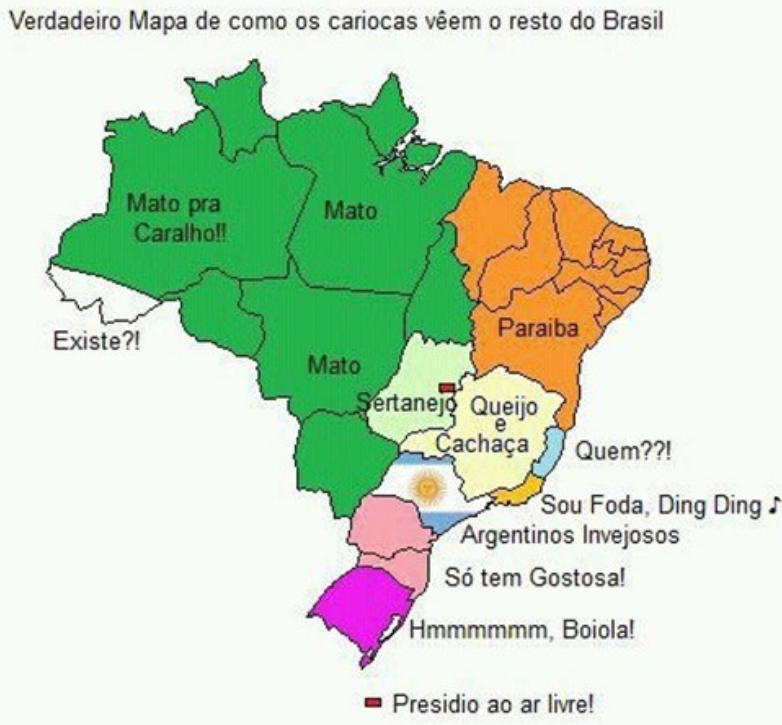

Fonte: VERDADEIRO mapa de como os cariocas veem o resto do Brasil. Diário do Rio. Disponível em: $<\mathrm{http}$ //diariodorio.com/wp-content/uploads/2011/10/Mapa-do-Rio-de-Janeiro-visto-pelos-cariocas.jpg $>$. Acesso em: 10 mar. 2016.

Figura 2 - Exemplo (2): Meme

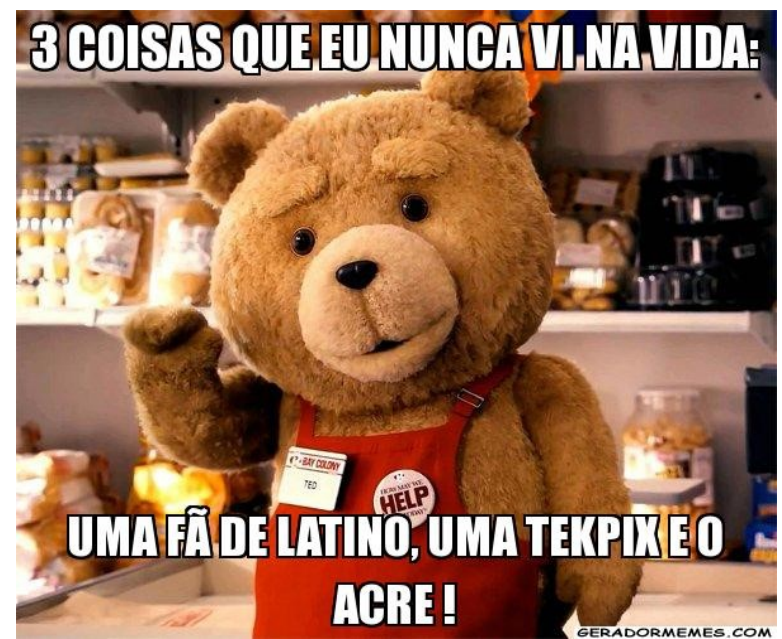

Fonte: 3 COISAS que eu nunca vi na vida. Geradordememe. Disponível em:

$<$ http://geradormemes.com/meme/5pqplg $>$. Acesso em: 10 mar. 2016.

No exemplo (1), tem-se um mapa que brinca com o modo como os moradores do estado do Rio de Janeiro veem o Brasil. O lugar que corresponderia ao Acre é identificado com uma pergunta: “Existe?”. Já em (2), tem-se um meme (algo que é imitado, uma brincadeira que se difunde rapidamente por redes sociais e que, em geral, é constituída por imagens e enunciados verbais) que destaca três coisas brasileiras jamais vistas: fã de Latino (cantor), tekpix (câmera fotográfica digital) e Acre (estado). Ambos os textos, cada um a seu modo, questionam a subsistência do estado. 
Os dois exemplos, como visto, não se referem somente ao Acre, mas incluem a localidade entre os dados mencionados para a produção do humor. Desse modo, de forma bem-humorada, ambos evidenciam uma identidade social (imagem negativa) construída para o Acre: a de ser um estado inexistente. A primeira pergunta que se levanta é se haveria motivo(s) para isso. Se sim, qual (quais) seria(m) ele(s)?

Levando-se em conta que os textos humorísticos são um material rico para refletir sobre construção identitária, este artigo pretende explicitar como a identidade social de estado inexistente, comumente edificada para o Acre nesses tipos de textos, é construída (e reforçada) por meio de expressões nominais com função: 1) referencial; 2) referencial e atributiva. Para isso, toma-se como corpus de análise exemplos de desnotícias, nome dado a textos publicados no site Desciclopédia, os quais parodiam notícias escritas por mídias de renome.

É relevante esclarecer que os excertos de desnotícias usados neste artigo para ilustrar a análise foram selecionados a partir de uma busca sobre o tema no site Desciclopédia. Em princípio, levantaram-se todas as desnotícias que versavam sobre o Acre em geral (um total de $32^{2}$ ), depois foram verificadas aquelas que atribuíam ao estado a identidade de inexistente. Neste caso, foram encontrados 10 exemplos.

Para além desse objetivo, qual seja, explicitar a construção da identidade social de estado inexistente, busca-se entender não apenas os motivos pelos quais o Acre é objeto de piada, mas também em que medida a história pode ou não explicar a construção bemhumorada de certa identidade social construída para o estado ${ }^{3}$, dado novo em relação ao tema e, por conta disso, ainda não explorado do ponto de vista teórico-científico (o que, por si só, já justificaria a necessidade da discussão em tela).

Há três hipóteses consideradas neste texto: a) que as expressões nominais referenciais e/ou referenciais e atributivas são um recurso eficaz na construção da identidade social do Acre; b) que as piadas sobre o Acre encontram explicação na história desse estado; c) que essas piadas forjam uma identidade para expressar efeitos de verdade.

O referencial teórico que fundamenta a análise empreendida neste estudo ancora-se em dois conceitos principais: identidade social e referenciação por meio de expressões nominais. Para discutir o primeiro, tomam-se como base os pressupostos da Análise de Discurso Crítica; para tratar do segundo, parte-se das considerações da Linguística Textual de base sociocognitiva e interacional. Antes, porém, de abordar tais conceitos, é importante esclarecer o que vem a ser desnotícia.

\footnotetext{
${ }^{2}$ As desnotícias que constam deste artigo fazem parte de um corpus maior, constituído de 32 exemplos, como citado. Para tal seleção, Silveira (2013) fez um levantamento da quantidade desses textos presentes no site Desciclopédia no período de 4 a 13 de abril de 2011, contabilizando um total 3.077 sobre assuntos variados. De todos os assuntos tratados, o estado do Acre era um dos temas mais abordado, tornando-se, portanto, o corpus de análise da pesquisadora.

${ }^{3}$ Convém destacar que não estamos afirmando que as identidades construídas social e culturalmente para o Acre, em textos humorísticos, correspondam de fato a uma verdade.
} 


\title{
De acordo com o site Desciclopédia, a desnotícia é definida como
}

\begin{abstract}
Uma fonte de notícias livre e de grátis, feita por pessoas e animais como você em mais de 25 mil idiomas. [...]. O seu conteúdo pode ser modificado, impresso e distribuído livremente para os seus amigos, ou para que você possa os colorir, saiba como! (Desnotícias: página principal, Desciclopédia, $\mathrm{s} / \mathrm{d}$ )
\end{abstract}

Trata-se de textos humorísticos que brincam com notícias veiculadas em alguma mídia de renome. Como registra de maneira bem-humorada o próprio enunciado, se até "animais como você" podem escrever e qualquer um pode editar ou modificar o seu conteúdo, as desnotícias se tornam informações nada confiáveis.

Os textos humorísticos, em oposição aos não humorísticos, definem-se pela perspectiva da comunicação não confiável. Conforme registra Travaglia (2015, p. 51), "há um rompimento do compromisso da comunicação com a seriedade, de ser algo válido em que se pode confiar, do princípio segundo o qual se alguém me diz algo, aquilo deve ser levado em conta com seriedade". Além disso, pode-se dizer que um ingrediente comum a essas produções seja o fator surpresa (cf. POSSENTI, 2010).

Para compreender melhor a desnotícia, faz-se necessário esclarecer de onde ela parte, ou melhor, o que vem a ser a Desciclopédia, veículo no qual tais textos são publicados. Lançado em 2006, o site é uma versão brasileira da Uncyclopedia. Ambas, a brasileira e a norte-americana, caracterizam-se por satirizar a página Wikipédia ${ }^{4}$, seja na forma de apresentação dos dados (layout), seja em relação aos diversos textos que ela publica.

Os diferentes conteúdos ali inseridos, que fazem parte de diversos gêneros (despoesias, desentrevistas, deslistas), são abertos para que usuários cadastrados os editem. Se o veículo (a Desciclopédia) que publica os textos por si só já é uma sátira, é coerente que seu conteúdo seja também de cunho humorístico.

No que tange às desnotícias, partindo de que se trata de "uma fonte de notícias livre e de grátis" (Desnotícias: página principal, Desciclopédia, s/d), buscou-se verificar se tais textos, embora de conteúdo humorístico, baseavam-se em matérias jornalísticas existentes e publicadas em portais jornalísticos. O estudo de Silveira (2013) comprova que sim. Ao comparar a notícia-fonte com a desnotícia, a autora nota que esta geralmente desconstrói o conteúdo do texto original, por meio de uma recontextualização.

Proposto por Fairclough (2003), o termo recontextualização implica transformação, uma vez que se refere ao fato de um texto/gênero ser posto em outro contexto. As desnotícias seriam, seguindo esse raciocínio, "a recontextualização de notícias reais em um texto parodístico, cujo propósito comunicativo é diferente do propósito da notícia” (SILVEIRA, 2013, p. 106). No caso das desnotícias usadas na análise deste artigo, notase que elas visam a ridicularizar o estado do Acre. A título de ilustração, vejamos um exemplo:

\footnotetext{
4 A Wikipédia é uma enciclopédia virtual que pode ser editada por seus usuários cadastrados e está disponível no endereço $<$ www.wikipedia.org.>
} 
(3) Desnotícia

PELOTAS, Estados Unidos do Sul - Numa região de montanhas geladas a oeste da Amazônia, numa área onde são raros os sinais de civilização, enormes antenas fazem um balé sincronizado. Ora viram para o poente, ora para o nascente. Para onde quer que apontem olham na direção do infinito e tentam responder a uma das questões mais antigas da humanidade: o Acre existe? (Pesquisadores procuram sinais do Acre, Desciclopédia, 16 jan. 2011)

\section{(4) Notícia}

Numa região de montanhas geladas ao norte da Califórnia, numa área onde são raros os sinais de civilização, enormes antenas fazem um balé sincronizado. Ora viram para o poente, ora para o nascente. Para onde quer que apontem olham na direção do infinito e tentam responder a uma das questões mais antigas da humanidade: estaremos, afinal, sozinhos neste universo? (Na Califórnia, pesquisadores procuram sinais de vida extraterrestre, G1, 18 nov. 2007)

O primeiro fragmento corresponde ao lead (nome do parágrafo de abertura do texto jornalístico, que tende a condensar os principais dados daquela informação) da desnotícia "Pesquisadores procuram sinais do Acre", postada no site Desciclopédia e atualizada em 16/01/2011. O segundo diz respeito ao lead da notícia que serviu de base, ou seja: "Na Califórnia, pesquisadores procuram sinais de vida extraterrestre", nota que foi publicada no portal G1 em 18/11/2007, na seção Ciência e Saúde.

Conforme se observa, a desnotícia funciona como uma espécie de paródia, visto que desloca o sentido do texto original para criticá-lo e/ou deformá-lo, ou seja, retrabalhase, no caso do corpus em questão, a notícia-fonte com o propósito de produzir humor, sem comprometimento com a verdade, mesmo que haja nesse texto uma crítica/denúncia social. De acordo com Silveira (2013), a desnotícia trata-se de um texto que recontextualiza fatos pertencentes ao contexto da notícia, a qual visa a informar a sociedade sobre acontecimentos cotidianos, para o contexto do humor: o fazer rir, divertir.

Ainda tomando como base o exemplo mencionado, especialmente o trecho "Para onde quer que apontem olham na direção do infinito e tentam responder a uma das questões mais antigas da humanidade: o Acre existe?", verifica-se que a paródia (vista na alteração de "estaremos, afinal, sozinhos neste universo?" para "o Acre existe?") busca não apenas divertir, mas construir para o Acre, de forma bem-humorada, a mesma identidade social vista nos casos já mostrados: a de estado inexistente. A questão que resta é saber por quê.

\section{IDENTIDADE SOCIAL E REFERENCIAÇÃO}

Herdeira dos estudos desenvolvidos pela Linguística Crítica, no final da década de 1970 - cujos propósitos eram compreender a linguagem e sua relação com o social e com as noções de ideologia e poder -, a Análise de Discurso Crítica (doravante ADC) consolida-se como disciplina no início da década 1990, tendo como expoente o linguista britânico Norman Fairclough.

Conforme Chouliaraki e Fairclough (1999), a ADC constitui um modelo teóricometodológico que se situa no âmbito da Ciência Social Crítica, estabelecendo um diálogo 
entre esse campo e a Linguística. Uma das características que define tal modelo, nas palavras de Ottoni (2014, p. 28), é que "o problema investigado é que vai demandar quais teorias entrarão nesse campo de diálogo".

Isso posto, o propósito principal da $\mathrm{ADC}$ é tratar de diversas práticas que compõem a vida social. Entre elas, está a construção de identidades sociais, que estão diretamente vinculadas ao conceito de discurso. Tais identidades, conforme Fairclough (2001), são estabelecidas nos e pelos discursos, de acordo com um projeto de dizer do falante/autor. Mas o que seria discurso, para o autor, nessa abordagem?

O conceito é concebido como "forma de prática social", que inclui não apenas uma forma de "representação do mundo", mas, também, de "significação do mundo" (FAIRCLOUGH, 2001, p. 90). Em suas considerações, o autor destaca que o discurso contribui para a construção de identidades sociais, de relações sociais entre as pessoas e de sistemas de conhecimento e crença. Silva (2009, p. 44), pesquisadora vinculada à ADC, que ampara seus estudos em Woodward (2000), salienta:

\footnotetext{
Um ponto consensual entre os pesquisadores é que as identidades não são um processo acabado, elas estão, por meio da linguagem, em constante construção e reconstrução. Assim, a linguagem é constitutiva do ser humano. E as identidades só adquirem sentido pela linguagem e pelos sistemas simbólicos que as representam
}

Tal abordagem pode ser relacionada com a perspectiva sociocognitiva da Linguística Textual, teoria com a qual será trabalhado o conceito de referenciação mais adiante. Para Silva (2009), as identidades estão em "constante construção e reconstrução". Isso ocorre, pois "o texto passa a ser considerado o próprio lugar da interação e os interlocutores, sujeitos ativos que - dialogicamente - nele se constroem e por ele são construídos" (KOCH, 2009, p. 33). Além disso, "a linguagem é tida como o principal mediador da interação entre as referências do mundo biológico e as referências do mundo sociocultural" (p. 32).

Essa visão de interação e de construção e reconstrução dos sujeitos por meio do texto pode ser relacionada com a afirmação de Silva (2009, p. 44), a de que "as identidades não são para sempre, e que a diferença ocorre com relação aos outros e com relação a elas mesmas, devido às transformações no tempo". Em outras palavras, os interlocutores, como sujeitos ativos, interagem por meio do texto construindo e reconstruindo identidades, tendo em vista que se trata de algo sempre em processo. Desse modo, a construção de identidade pode sofrer modificação à medida que o tempo passa.

Com relação às identidades atribuídas a determinada nação (e, por que não dizer, a certa região ou certo estado de um país), é importante acrescentar, com base em Hall (2006), que elas advêm não apenas das histórias que são contadas sobre a nação, memórias que conectam seu presente com seu passado (panoramas, eventos históricos, símbolos, rituais) e imagens que dela são construídas, mas, também, do conjunto de práticas que buscam articular certos valores e normas de comportamento, por meio da repetição. Os exemplos citados até o momento neste artigo tendem a reforçar, de forma bem-humorada, que o estado do Acre não existe. 
Em suma, o discurso tem alguns efeitos constitutivos e um deles é o de contribuir para a construção de identidades sociais e culturais. Identidades que, nesta discussão, são compreendidas como uma representação imaginária, que pode ou não ter amparo no real e que, portanto, pode ou não ser explicada por questões históricas. Além disso, mesmo que as representações se vinculem à História, isso não significa que elas, de fato, sejam verdadeiras, já que a desnotícia descontrói os fatos aos quais faz referência.

Desse modo, as identidades - que se ligam à cultura, às relações sociais e aos elementos históricos - são, portanto, construções que levam em conta aspectos que refletem indivíduos, lugares. Nesse sentido, as representações sociais e culturais, manifestadas nos textos de humor que brincam com a inexistência do Acre, consistem em vetores potenciais de processos identitários de manutenção e/ou reconstrução de identidades desse estado brasileiro, nesse contexto.

Considerando-se que o objetivo deste artigo é refletir sobre uma das identidades construídas para o Acre (a de estado inexistente) por meio de processo de referenciação - mais especificamente a partir de expressões nominais referenciais e/ou referenciais e atributivas que remetam a ele -, faz-se necessário tratar aqui de cada um desses conceitos.

O fenômeno da referenciação é abordado por diferentes correntes teóricas. Do ponto de vista da Linguística Textual de base sociocognitiva e interacional, perspectiva da qual se parte, trata-se de uma operação discursivamente produzida, na qual os sujeitos constroem objetos de discurso (MONDADA, DUBOIS, 2003; APOTHÉLOZ, REICHLER-BÉGUELIN, 2003). Esses objetos são definidos como "entidades que são interativamente e discursivamente produzidas pelos participantes no fio da enunciação" (MONDADA, 2001, p. 9).

De acordo com pesquisadores brasileiros que abordaram o tema ${ }^{5}$, a referenciação é concebida como uma "atividade discursiva", na qual o sujeito, "por ocasião da interação verbal, opera sobre o material linguístico que tem à sua disposição, realizando escolhas significativas para representar estados de coisas" a fim de construir um determinado sentido (KOCH, 2005, p. 34-35). Por esse olhar, trata-se de uma atividade cognitivodiscursiva, cujo processamento é estratégico.

Tal processo, que se caracteriza pela introdução (ativação, categorização) e retomada de objetos de discursos (reativação, recategorização), pode ser estabelecido por expressões tanto de ordem gramatical (como pronomes e numerais), quanto lexical (formas ou grupos nominais). Dentre essas expressões, interessam as de ordem lexical, dado o fato de que elas podem ser as responsáveis por construir identidades.

Compostas em geral por um nome (substantivo) que pode ser acompanhado de um determinante (indefinido, definido ou demonstrativo) ou de um modificador (adjetivo, sintagma preposicional, oração relativa), as expressões nominais podem ser: 1) referenciais; 2) referenciais e atributivas. O primeiro caso refere-se "àquelas que identificam ou designam um objeto de discurso"; já o segundo diz respeito às "que atribuem predicados a um objeto de discurso instituído" (CARMELINO, 2015, p. 96).

\footnotetext{
${ }^{5}$ Caso de Marcuschi (2000), Koch (2005) e Cavalcante (2011).
} 
Se a escolha das palavras que compõem as expressões nominais referenciais e/ou referenciais e atributivas é feita pelo produtor do texto de acordo com um projeto de dizer (a fim de veicular certo efeito de sentido), muitas vezes, são essas formas as responsáveis por construir identidades sociais, além de revelar pontos de vista e fazer avaliações.

Nesse sentido, o processo de referenciação por meio de tais expressões pode ser articulado à proposta de Fairclough (2001, p. 104), quando nos diz que: "as pessoas fazem escolhas sobre o modelo e a estrutura de suas orações que resultam em escolhas sobre o significado (e a construção) de identidades sociais, relações sociais e conhecimento e crença". Ainda a esse respeito, convém mencionar o que registra Ottoni (2007, p. 47): "Muitas palavras que nós escolhemos para descrever alguma coisa ou alguém veiculam uma atitude positiva ou negativa [...] Isso vai depender de nossa posição [...] de como queremos nos posicionar e também posicionar o ouvinte/leitor de nosso texto".

Com base nessas considerações e na análise de fragmentos de desnotícias, busca-se mostrar no próximo tópico como algumas expressões nominais referenciais e/ou referenciais e atributivas constituem estratégias representacionais para reiterar certa identidade social que circula na mídia (em especial em textos de humor) sobre o Acre: a de que esse estado brasileiro não existe.

\section{ESTADO INEXISTENTE: IDENTIDADE SOCIAL CONSTRUÍDA PARA O ACRE}

As piadas ou os textos de humor em geral, por veicularem discursos menos oficiais, podem além de criticar, pôr em evidência certos modos de ser e estar, representações identitárias. Uma identidade social comumente construída para o Acre nas chamadas desnotícias, que reforça o que já foi explicitado nos exemplos citados ao longo deste texto, é a de estado inexistente.

Haveria alguma explicação (de ordem histórica ou não) para isso? Antes de dar qualquer resposta para a questão levantada, vejamos como tal identidade se manifesta por meio de diferentes expressões nominais com função referencial e/ou referencial e atributiva que remetem ao estado. Comecemos por dois exemplos:

(4) “Antigamente pertencente à Bolívia, foi trocado por um cavalo com o Brasil, porém como até hoje ninguém achou o local, o cavalo continua no Brasil, estacionado em frente a [sic] embaixada boliviana em Brasília, esperando a comprovação da existência do Acre". (Lula coloca Acre no fuso horário brasileiro na tentativa de encontrá-lo, Desciclopédia, 16 jan. 2011 - grifo nosso)

(5) "Até mesmo entre os grandes cientistas, discutir a existência do Acre é tão complicado quanto discutir política ou religião" (Pesquisadores procuram sinais do Acre, Desciclopédia, 16 jan. 2011 - grifo nosso)

Os excertos - que fazem parte das desnotícias "Lula coloca Acre no fuso horário brasileiro na tentativa de encontrá-lo" e "Pesquisadores procuram sinais do Acre" questionam, cada um a seu modo, a existência do Acre. Isso pode ser observado tanto pela expressão nominal "a existência do Acre", com função referencial, quanto pelos 
termos que fazem parte de seu entorno. Formada por um determinante definido $(a)$, um substantivo (existência) e um sintagma preposicional (do Acre), a expressão nominal chama a atenção especialmente pela presença do termo existência. Não é comum usá-lo para se referir a algo que, efetivamente, exista. Portanto, quando o leitor se depara com tal expressão, surpreende-se por ser afirmado algo tão óbvio, acarretando, assim, o efeito humorístico do texto e a depreciação do estado do Acre, que passa a ter sua existência questionada.

Em (4), a construção "esperando a comprovação da", que antecede a forma nominal, permite que se compreenda que a existênca do Acre ainda não foi confirmada, porque não haveria provas certificando o fato (espera-se pelo acontecimento). Em (5), ao explicitar que a existência do Acre seja algo complicado de ser discutido "até mesmo entre grandes cientistas", como é o caso de política e religião, sugere-se que existam assuntos delicados, polêmicos, sobre os quais ainda não há um consenso, uma única opinião formada. E a existência do Acre é um desses assuntos.

Outra expressão nominal, agora com função referencial e atributiva, que reitera a identidade social do Acre como inexistente, é a que o mostra como "o estado perdido", como podemos ver no fragmento que segue:

(6) RIO BRANCO, Ilha de Lost Acre - O presidente Luís Fusohorácio Lula da Silva sancionou hoje a lei que institui o mesmo fuso horário do Oeste do Brasil para o Acre. A medida visa facilitar a vida das inúmeras expedições exploratórias que buscam o Estado Perdido. (Lula coloca Acre no fuso horário brasileiro na tentativa de encontrá-lo, Desciclopédia, 15 jan. 2011 - grifo nosso)

Constituída por um determinante definido (o), um substantivo (estado) e um adjetivo (perdido, daí o caráter atributivo), a escolha lexical, no caso dessa expressão, mostra-se essencial para produzir o efeito de sentido pretendido pelo autor. $\mathrm{O}$ determinante $o$ indica que não é qualquer estado que está sendo procurado, mas apenas um, o Acre. O termo perdido significa não ter mais (por consequência, não existir). Se algo é perdido, nesse caso, passa a ser inexistente, de certa forma. Com base na história do Acre, pode-se inferir que se trata de um estado desaparecido ou esquecido, talvez por estar situado muito distante dos grandes centros brasileiros, como Rio de Janeiro, São Paulo, Distrito Federal.

Alguns elementos do entorno da expressão corroboram um sumiço definitivo (daí a inexistência), como "A medida visa [instituir o mesmo fuso horário do Oeste do Brasil para o Acre, a fim de encontrá-lo] facilitar a vida das inúmeras expedições exploratórias que buscam o Estado Perdido". Há outro exemplo cuja expressão nominal semelhante, "Estado Brasileiro Perdido", acena para o mesmo sentido, a diferença é que ela caracteriza explicitamente o Acre como um estado brasileiro, como se verifica em:

(6) Suspeitas recaem que o estado localize-se [sic] no meio da Amazônia, à frente da República Checa e atrás do Peru, mas nenhum governante destes locais confirma o fato. Enquanto isso, a ONU preocupada com os fracos e oprimidos, mandou sua $69^{\mathrm{a}}$ missão em busca do Acre e a NASA já preparou o lançamento da $42^{\mathrm{a}}$ sonda em busca do "Estado Brasileiro Perdido". (Acre é o local que mais aparece no Google Earth diz pesquisa, Desciclopédia, 15 jan. 2011 - grifo nosso) 
No exemplo (7), temos uma expressão nominal referencial e atributiva, "Estado Brasileiro Perdido", que sugere uma possível mudança no nome do estado, pois as iniciais estão em letra maiúscula, igual a um nome próprio. Isso nos chama a atenção, já que recategoriza o objeto do discurso Acre, caracterizando-o principalmente como perdido. Tal adjetivação avalia, como visto no excerto (5), o Acre como um estado desaparecido ou esquecido. Além disso, pode-se retomar a história do Acre para se compreender o uso do adjetivo perdido, tendo em vista que o Brasil quase se envolveu em uma Guerra com a Bolívia para não perder o território que hoje é o Acre. Nesse caso, a desnotícia se baseia na história para satirizar a luta pela posse da área correspondente a tal estado.

Outra possibilidade de entendimento inferida é a de que o Acre tenha sido destruído de maneira definitiva, pois perdido também tem esse significado (ser arruinado, aniquilado). No entanto, o uso do sintagma preposicional em busca de, que antecede e introduz a expressão nominal aqui analisada, leva-nos a interpretar a noção de perdido como desaparecido, pois evidencia a possibilidade de desaparecimento ou sumiço do estado, uma vez que o uso do verbo buscar, nessas expressões, tanto em (6) quanto em (7), assumem o mesmo valor de procurar, e se tende a buscar aquilo que foi perdido.

Os próximos dois excertos, (8) e (9), caracterizam-se por fazer referência indireta ao Acre, mas não deixando de reforçar a costrução da identidade de estado inexistente, pois destacam a capital e o exército ao fazerem uso dos mesmos adjetivos: suposto e inexistente:

(7) No mapa do Brasil que servia como ponto de partida para as matérias sobre as cidades, Rio Branco, a "suposta" capital do Acre, foi apontada na região onde de fato está localizada. (FIFA comprova o óbvio: o Acre não existe!, Desnotícia, 15 jan. 2011 - grifo nosso)

(8) O Exército Bahiano perdeu, neste domingo, sua invencibilidade diante do suposto exército acriano inexistente. [...] Diversos moradores das cidades que fazem divisa com o Acre tem [sic] visto mobilizações de diversos animais azuis voadores se reunindo na inexistente capital acreana [sic]. (Portal Terra relata nova Guerra do Acre, Desnotícia, 16 jan. 2011 - grifos nossos)

No fragmento (8), a expressão destaca a capital "Rio Branco" e, em seguida, é utilizado um aposto explicativo, "a 'suposta' capital do Acre”. No aposto, constituído por uma expressão nominal referencial e atributiva, o que se destaca é o adjetivo suposto que caracteriza a capital do Acre, Rio Branco. As aspas sugerem uma construção irônica do tipo: todos sabem que não existe a capital do Acre, o que já seria algo óbvio. Com isso, reafirma-se a subsistência do estado, tendo como ponto de partida a não existência de sua capital. Seria um caso de metomínia, a parte pelo todo, se a capital não existe, o mesmo vale para o estado que supostamente a abrigaria. Outro fato que salienta a não existência do Acre, nesta desnotícia, é o próprio título dela: "FIFA comprova o óbvio: o Acre não existe!".

Em (9), "o suposto exército acriano inexistente", o mesmo adjetivo não mais se encontra entre aspas, mas modifica o sentido de "exército acriano", o que coloca em questão a presença de um exército no estado. Entretanto, a dúvida é resolvida ao final da 
expressão, por meio do adjetivo inexistente, que indica que seja um estado desprotegido, pois não há um órgão público para defendê-lo. Além disso, esse adjetivo é utilizado novamente no fragmento (9), "a inexistente capital acreana". Apesar de os fragmentos (8) e (9) serem de desnotícias diferentes, ambos têm o mesmo propósito: evidenciar a não existência da capital acreana e, assim, consequentemente, anular a existência do estado.

Por fim, uma última desnotícia que corrobora a identidade social de estado inexistente por meio da expressão nominal referencial e atributiva "uma invenção do governo", que pode se vista no trecho a seguir:

(9) Muito provavelmente você ja percebeu onde queremos chegar... Não, o Acre não existe, ele é apenas uma invenção do governo a fim de esconder uma área secreta onde estão mantidas as tampas de caneta bic (perdidas), os políticos honestos e os Chesters. (Google nega ter apagado o Acre do serviço GoogleMaps, Desnotícia, 18 jan. 2011 - grifo nosso)

A expressão em destaque no excerto (10) é constituída por um determinante indefinido (uma), um substantivo (invenção) e um sintagma preposicional (do governo). Nela, o termo que é ressaltado na constituição da identidade é invenção, pois sugere que o Acre seja uma fantasia (algo que não existe). Esse dado é confirmado pela definição do próprio vocábulo: "invenção: coisa imaginada ou inventada com astúcia ou má-fe; invencionice, maquinação, mentira" (FERREIRA, 1999).

Além disso, deve-se levar em conta que o estado não é uma invenção feita por qualquer um, mas, sim, pelo governo. A fim de se compreender melhor a escolha lexical do governo, é preciso conhecer a história do Acre, para saber que ele foi comprado da Bolívia, pelo Brasil, por duas mil libras esterlinas. Com base nisso, se a desnotícia diz que o governo o inventou, certamente é para desconstruir a história do Acre e colocar em dúvida se ele realmente existe, já que pouco se fala, atualmente, nas escolas e na mídia sobre as brigas territoriais que ocorreram entre Bolívia, Peru e Brasil, por causa do Acre.

A partir dos exemplos aqui apresentados, é possível verificar que as expressões nominais com função referencial e/ou referencial atributiva que remetem ao Acre mostram esse estado brasileiro como aquele que não subsiste como espaço físico e, por isso, não possui uma capital, nem mesmo habitantes.

Ao colocar em questão (ora de forma implícita, ora de forma escancarada) a (não) existência do Acre, as desnotícias tendem, pelo viés do humor, a construir uma imagem (identidade social) negativa dele. Imagem esta que, além de ridicularizá-lo, rebaixa-o a ponto de anulá-lo.

Embora o rebaixamento seja uma forma bastante comum de se produzir humor, é preciso refletir sobre seus efeitos de sentido que, certamente, têm uma razão de ser. A explicação para se fazerem tantas piadas com/sobre o Acre (um dentre os 26 estados brasileiros e o Distrito Federal), segundo se entende, não está no acaso, mas na sua própria história. Em razão disso, na sequência, serão abordados alguns fatos que marcaram a trajetória do estado, a fim de se compreender o porquê de edificá-lo por meio de certa imagem. 
Sobre o Acre, o que imediatamente nos chama a atenção não é o fato de ele ser um estado novo, se comparado a Minas Gerais, São Paulo ou Bahia. Quanto a esse tópico, há o Tocantins, que é o mais recente território elevado ao status de estado. Em termos sóciohistóricos, chamam a atenção dois dados: o Acre quase não ser noticiado e ter sido um estado comprado.

Retomando a sua história, até 1901, o Acre pertencia à Bolívia e era um território habitado pelos índios. Entretanto, em meados do ano de 1877, brasileiros provenientes do Nordeste passaram a ocupá-lo com o objetivo de extrair o látex ${ }^{6}$, principal matéria-prima da região. Por causa da chegada dos brasileiros, o governo imperial brasileiro assinou o Tratado de Ayacucho, que fixou áreas limítrofes entre as duas nações.

Tal acordo não foi suficiente para evitar conflitos entre os dois países. Conforme Gurgelm (2003), no período de 1899 a 1903, o Brasil e a Bolívia quase declararam guerra por causa das brigas territoriais. Nesse contexto de lutas (visto que a maioria do território do Acre tinha sido ocupada por brasileiros), em 14 de julho de 1901, Luís Galvez, conhecido como "o Imperador do Acre", decidiu proclamá-lo estado independente.

Nas palavras de Neves (2013), em novembro de 1903, o Acre foi anexado ao Brasil como Território Federal, tendo os poderes judiciário e legislativo sido implantados de forma lenta e irregular. O Atlas National Geographic: Brasil (2008) registra que, após a assinatura do Tratado de Petrópolis (um acordo diplomático proposto pelo Barão do Rio Branco $^{7}$ ), o governo brasileiro pagou dois milhões de libras esterlinas à Bolívia e prometeu construir a estrada de ferro Madeira-Mamoré para facilitar o escoamento de produtos bolivianos para o Atlântico. Isso deixa claro que o Acre foi um território comprado.

Convém assinalar que a ascensão do Acre como estado só ocorreu em 15 de junho de 1962, por meio da lei 4.070, sancionada pelo Presidente da República João Goulart. Nesse período, o estado teve como governador José Augusto de Araújo, eleito em outubro de 1962.

Atualmente, sabe-se muito pouco sobre o Acre, pois, como já dito, trata-se de um estado que não é noticiado na chamada grande mídia, nem considerado como local que apresenta algum ponto turístico de destaque no país. Pode-se, entretanto, ressaltar que ele ocupa uma área de $164.123 .040 \mathrm{~km}^{2}$, o que equivale a menos de $2 \%$ da superfície do país.

De acordo com o censo do IBGE de 2013, o Acre é o terceiro estado menos populoso do país. Ele ocupa ainda o $22^{\circ}$ lugar no índice de desenvolvimento em pesquisa realizada pela Fundação Carlos Chagas e o $24^{\circ}$ lugar dos melhores estados em condições de vida, do estudo realizado pela consultoria Macroplan (2004).

\footnotetext{
${ }^{6}$ De acordo com o Atlas (2008, p. 48), “a extração de látex sustentou o ciclo da borracha um século atrás e ainda é uma das principais atividades econômicas do Acre”.

${ }^{7} \mathrm{O}$ tratado de Petrópolis representa uma das maiores vitórias diplomáticas do Brasil, visto que conseguiu incorporar ao território nacional, sem deflagrar guerra, uma extensão de terra de quase $200.000 \mathrm{~km}^{2}$, que foi entregue a 60 mil seringueiros e suas famílias para que lá pudessem exercer as funções extrativas da borracha.
} 
Diante do exposto, considera-se a hipótese de que a história do Acre explica as piadas e a identidade social bem-humorada que se constrói para o estado em textos que circulam na Internet. Os dados mais relevantes parecem ser o fato de se localizar numa região bastante isolada, ou seja, distante dos grandes centros urbanos ditos mais importantes (como os da região Sudeste), não ter pontos turísticos para visitação e não ser noticiado na grande mídia (rádio, TV, jornais). Isso reforça a construção da imagem do Acre como um estado sem importância, esquecido e, por consequência, alvo de textos que questionam a sua existência, apontando-o como inexistente.

Se, como dito no início deste texto, há motivos para se fazer piadas com algo ou alguém, no caso em questão, as piadas sobre o Acre cumprem funções de extrema relevância. Ao afirmarem insistentemente, e de diferentes formas, que o estado não existe (o que não é verdade), os textos humorísticos buscam, pela simulação, não só reafirmar a subsistência desse estado, mas também colocá-lo em evidência no cenário brasileiro, fazendo com que ele seja lembrado, notado.

Desse modo, além de forjar, para expressar efeitos de verdade (já que a inexistência do Acre é inventada para destacar uma possível verdade a seu respeito: o esquecimento), outra função das piadas sobre o Acre é a denúncia à condição específica a que esse estado parece estar submetido: a de anulado.

\section{CONSIDERAÇÕES FINAIS}

Neste artigo, procurou-se evidenciar como o processo de referenciação feito por expressões nominais referenciais e/ou referenciais e atributivas constrói determinada identidade social para o estado do Acre, tornando-o motivo de piada. A esse respeito, convém destacar que as escolhas lexicais que constituem tais expressões são significativas para construir certas representações, independentemente de serem verdadeiras ou não.

Além disso, destacou-se que as desnotícias são textos humorísticos que recontextualizam dados de matérias jornalísticas existentes (e sérias). No caso em questão, certas notícias foram transformadas em piadas sobre o Acre especialmente por meio das expressões nominais, como é o caso dos exemplos "o Estado Perdido", "Rio Branco, a "suposta" capital do Acre", "uma invenção do governo". Pode-se dizer, portanto, que tais formas constituem um recurso eficaz tanto na deflagração da identidade social do Acre de ser um estado inexistente, quanto na produção de textos humorísticos.

Ainda tomando como base a análise das expressões que compõem o corpus deste artigo, verificou-se que a identidade construída para o Acre é negativa, algo que tende a rebaixá-lo e a anulá-lo como estado. Tal fato - a sua inexistência - pode ser justificado pelas condições sócio-históricas da constituição do Acre como estado, que, como exposto no decorrer deste estudo, mostram que ele tem pouco destaque na sociedade brasileira (seja pela localização geográfica, seja por não possuir pontos turísticos), sendo assim pouco noticiado e, portanto, sendo esquecido. 
ACRE. In: Atlas National Geographic - Brasil. São Paulo: Abril, v. 13, 2008.

ACRE é o local que mais aparece no Google Earth diz pesquisa. Desciclopédia, 15 jan. 2011. Disponível em:

$<\mathrm{http}: / /$ desciclopedia.ws/wiki/Desnot\%C3\%ADcias:Acre_\%C3\%A9_o_local_que_mais_aparece_no_Go ogle_Earth_diz_pesquisa>. Acesso em: 10 mar. 2016.

APOTHÉLOZ, D.; REICHLER-BÉGUELIN, M-J. Construction de la référence et stratégies de designation. In: ADAM, J-M (Org.). Du sintagme nominal aux objets-de-discours. Neuchâtel: Université de Neuchâtel, 1995. p. 142-173. Obra em português: Construção dos objetos do discurso: uma abordagem dos processos de referenciação. In: CAVALCANTE, M. M.; RODRIGUES, B. B.; CIULLA, A. (Orgs.). Referenciação. São Paulo: Contexto, 2003. p. 17-52.

CARMELINO, A. C. Expressões nominais referenciais e construção do humor. In: CARMELINO, A. C. Humor: eis a questão (Org.). São Paulo: Cortez, 2015. p. 91-115.

CAVALCANTE, M. M. Referenciação: sobre coisas ditas e não ditas. Fortaleza: Edições UFC, 2011.

CHOULIARAKI, L.; FAIRCLOUGH, N. Discourse in late modernity: rethinking Critical Discourse Analysis. Edinburgh: Edinburgh Uiniversity Press, 1999.

DESNOTÍCIAS: página Principal. Desciclopédia. Disponível em:

$<$ http://desciclopedia.org/wiki/Desnot\%C3\%ADcias:P\%C3\%A1gina_principal $>$. Acesso em 10 mar. 2016.

FAIRCLOUGH, N. Discurso e mudança. Coord. de trad. Izabel Magalhães. Brasília: Editora Universidade de Brasília, 2001. - Analysing discourse: textual analysis for social research. London/New York: Routledge, 2003.

FERREIRA, A. B. H. Novo Aurélio século XXI: o dicionário de língua portuguesa. 3. ed. Rio de Janeiro: Nova Fronteira, 1999.

FIFA comprova o óbvio: o Acre não existe! Desciclopédia, 15 jan. 2011. Disponível em: $<$ http://desciclopedia.ws/wiki/Desnot $\%$ C3\%ADcias:FIFA_comprova_o_\%C3\%B3bvio:_o_Acre_n\%C3 \%A3o_existe!>. Acesso em: 10 mar. 2016.

GOOGLE nega ter apagado o Acre do serviço GoogleMaps. Desciclopédia, 18 nov. 2008. Disponível em: $<$ http://desciclopedia.org/wiki/Desnot\%C3\%ADcias:Google_nega_ter_apagado_o_Acre_do_servi\%C3\% A7o_GoogleMaps>. Acesso em: 10 mar. 2016.

GURGELM, R. Brasil X Bolívia: a guerra evitada. Educação Terra, 12 nov. 2003. Disponível em: $<$ http://educaterra.terra.com.br/voltaire/brasil/2003/11/12/001.htm>. Acesso em: 10 mar. 2016.

HALL, S. A identidade cultural na pós-modernidade. Trad. de Tomaz Tadeu da Silva, Guacira Lopes Louro. 11. ed. Rio de Janeiro: DP\&A, 2006.

HALLIDAY, M. A. K. Introduction to functional grammar. London: Edward Arnold, 1985.

KOCH, I. G. V. Desvendando os segredos do texto. 4. ed. São Paulo: Cortez, 2005.

Introdução à linguística textual: trajetória e grandes temas. 2. ed. São Paulo: Editora Martins Fontes, 2009.

LULA coloca Acre no fuso horário brasileiro na tentativa de encontrá-lo. Desciclopédia, 16 jan. 2011. Disponível em:

$<$ http://desciclopedia.ws/wiki/Desnot\%C3\%ADcias:Lula_coloca_Acre no fuso_hor\%C3\%A1rio_brasile iro_na_tentativa_de_encontr\%C3\%A1-lo>. Acesso em: 10 mar. 2016.

MACROPLAN. Desafios da gestão estadual, versão 2014. Disponível em:

<file://C:/Users/Ana\%20Cristina/Downloads/Desafios_da_Gestao_Estadual.pdf>. Acesso em: 10 mar. 2016.

MARCUSCHI, L. A. Quando a referência é uma inferência. Estudos Linguísticos, Assis, p. 1-31, 2000. MONDADA, L. Gestion du topic et organization de la conversation. Cadernos de Estudos Linguísticos, Campinas, n. 41, 2001, p. 7-36.

MONDADA, L.; DUBOIS, D. Construction des objets de discours et catégorisation: une approche des processus de référenciation. Paris: Travel, 1995. Obra em português: Construção dos objetos do discurso: 
uma abordagem dos processos de referenciação. In: CAVALCANTE, M. M.; RODRIGUES, B. B.; CIULLA, A. (Orgs.). Referenciação. São Paulo: Contexto, 2003, p. 17-52.

NA CALIFÓRNIA, pesquisadores procuram sinais de vida extraterrestre. G1, 18 nov. 2007. Disponível em: $<$ http://g1.globo.com/Noticias/Ciencia/0,,MUL184465-5603,00-

NA+CALIFORNIA+PESQUISADORES+PROCURAM+SINAIS+DE+VIDA+EXTRATERRESTRE.ht $\mathrm{ml}>$. Acesso em: 10 mar. 2016.

NEVES, M. V. História Política do Acre. Papos do primeirão, 21 nov. 2013. Disponível em: $<$ http://paposprimeirao.blogspot.com.br/2013/11/historia-politica-do-acre-i-escrito-por_21.html $>$. Acesso em: 10 mar. 2016.

OTTONI, M. A. R. Os gêneros do humor no ensino de Língua Portuguesa: uma abordagem discursiva crítica. 2007, 399f. Tese (Doutorado em Linguística) - Universidade de Brasília, Brasília, 2007.

As representações identitárias de gênero no humor sexista. In: OTTONI, M. A. R.; LIMA, M. C. (Org.). Discursos, identidades e letramentos: abordagens da análise de discurso crítico. São Paulo: Cortez, 2014. p. 25-62.

PESQUISADORES procuram sinais do Acre. Desciclopédia, 16 jan. 2011. Disponível em: $<\mathrm{http} / / /$ desciclopedia.ws/wiki/Desnot\%C3\%ADcias:Pesquisadores procuram sinais do Acre>. Acesso em: 10 mar. 2016.

PORTAL Terra relata nova Guerra do Acre. Desciclopédia, 16 jan. 2011. Disponível em: $<$ http://desciclopedia.ws/wiki/Desnot\%C3\%ADcias:Portal_Terra_relata_nova_Guerra_do_Acre $>$. Acesso em: 10 mar. 2016.

POSSENTI, S. Humor, língua e discurso. São Paulo: Contexto, 2010.

SILVA, F. C. O. O uso de metáforas e a construção de identidades étnicas. In: VIEIRA, J. A. et al. Olhares em análise de discurso crítica. Brasília: Josenia Antunes Vieira, 2009.

SILVEIRA, K. Desnotícias sobre o Acre: a construção do humor e de Identidades sociais. $142 \mathrm{f}$. Dissertação (Mestrado em Linguística) - Universidade Federal do Espírito Santo, 2013.

TRAVAGLIA, L. C. Texto humorístico: o tipo e seus gêneros. In: CARMELINO, A. C. Humor: eis a questão (Org.). São Paulo: Cortez, 2015. p. 49-90.

VERDADEIRO mapa de como os cariocas vêem o resto do Brasil. Diariodorio. Disponível em: $<\mathrm{http}$ //diariodorio.com/wp-content/uploads/2011/10/Mapa-do-Rio-de-Janeiro-visto-pelos-cariocas.jpg>. Acesso em 10 mar. 2016

WOODWARD, K. Identidade e diferença: uma introdução teórica e conceitual. In: SILVA, T. T. da (Org.). Identidade e diferença. São Paulo: Vozes, 2000.

Recebido em: 12/03/16. Aprovado em: 21/08/16.

Título: Does not Acre exist? In unnews, it does not

Authors: Ana Cristina Carmelino; Karine Silveira

Abstract: In this study the main aim is to show how referential and/or referential and attributive nominal expressions are able to build a social identity to Acre's state. To do it, unnews were analyzed. Unnews are humoristic texts posted in Desciclopedia site that parody news from different media. The theoretical discussion is based on the concepts of social identity and referential process, both formulated by Critical Discourse Analysis and Textual Linguistics. The present study explains that the terms selection which composes nominal expressions is responsible for producing different meaning effects. In our analysis the goal of this type of text is to build humorous social identities, as long as the nominal expressions doubt about Acre's existence. In our point of view, this strategy shows that this state became a reason for making jokes.

Keywords: Social identity. Referential process. Unnews. Humor. Acre. 
Título: ¿Acre no existe? En desnoticias, no

Autoras: Ana Cristina Carmelino; Karine Silveira

Resumen: En este artículo, el objetivo es mostrar que la referencia hecha por expresiones y/o referencias nominal y expresiones atributivas es capaz de construir cierta identidad social para el estado de Acre. Para ello, se analizan desnoticias, el nombre dado a los textos humorísticos publicados en el sitio Desciclopedia parodiando noticias escritas por los medios reconocidos. La discusión teórica está anclada en especial en los conceptos de identidad social y referenciación, hechos respectivamente por el Análisis Crítico del Discurso y la Lingüistica Textual. El estudio explica que la selección de los términos que conforman las expresiones nominales es responsable por generar determinados efectos de sentido. En este caso, buscamos construir la identidad social de manera humorística, ya que esas formas ponen en duda existencia de Acre, tornando ese estado en hazmerreír.

Palabras-clave: Identidad social. Proceso referencial. Desnoticia. Humor. Acre.

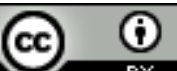

Este texto está licenciado com uma Licença Creative Commons Atribuição 4.0 Internacional. 